\title{
Young-onset type 2 diabetes in South Korea: a review of the current status and unmet need
}

\author{
Ye Seul Yang ${ }^{1,}$, Kyungdo Han ${ }^{2,}$, Tae Seo Sohn ${ }^{1}$, and Nam Hoon Kim ${ }^{3}$
}

\begin{abstract}
${ }^{1}$ Division of Endocrinology and Metabolism, Department of Internal Medicine, Uijeongbu St. Mary's Hospital, College of Medicine, The Catholic University of Korea, Seoul; ${ }^{2}$ Department of Statistics and Actuarial Science, Soongsil University, Seoul; ${ }^{3}$ Division of Endocrinology and Metabolism, Department of Internal Medicine, Korea University College of Medicine, Seoul, Korea
\end{abstract}

Received: August 17, 2021 Accepted: August 26, 2021

\section{Correspondence to}

\section{Nam Hoon Kim, M.D.}

Division of Endocrinology and Metabolism, Department of Internal Medicine, Korea University Anam Hospital, 73 Goryeodae-ro, Seongbuk-gu, Seoul 02841, Korea Tel: +82-2-920-5421

Fax: +82-2-953-9355

E-mail: pourlife@korea.ac.kr https://orcid.org/0000-00029926-1344

*'These authors contributed equally to this work.
The prevalence of young-onset (diagnosis at age $<40$ years) type 2 diabetes mellitus $(\mathrm{T} 2 \mathrm{DM})$ is increasing globally. Young-onset T2DM has a common pathophysiology of glucose dysregulation as in late-onset T2DM. However, it presents a greater association with obesity and a more rapid decline in $\beta$-cell function than late-onset T2DM. Accumulating evidence indicates that disease progression in young-onset $\mathrm{T} 2 \mathrm{DM}$ is rapid, resulting in early and frequent development of microvascular and macrovascular complications, as well as premature death. Improper management and low adherence to medical therapy are important issues in young-onset $\mathrm{T} 2 \mathrm{DM}$. This review discusses the epidemiology, disease entity, and clinical issues associated with young-onset T2DM. We also present the prevalence and clinical characteristics of patients with young-onset T2DM in South Korea.

Keywords: Diabetes mellitus, type 2; Young adult; Diabetes complications; Epidemiology; Treatment adherence and compliance

\section{INTRODUCTION}

Type 2 diabetes mellitus ( $\mathrm{T} 2 \mathrm{DM})$ is commonly observed in middle-aged or elderly people but is increasingly being diagnosed in younger adults, accompanied by an increase in obesity. Accumulating evidence indicates that young-onset (diagnosis at age $<40$ years) $\mathrm{T} 2 \mathrm{DM}$ (YOD) presents aggressive phenotype associated with an increased risk of complications and death compared with late-onset T2DM [1]. Early-onset of diabetes leads to prolonged exposure to high blood glucose levels and, consequently, a greater risk of chronic vascular complications. In addition, it is difficult to maintain a healthy lifestyle and to adhere to pharmacological treatments over a longer period. The onset of $\mathrm{T} 2 \mathrm{DM}$ at a young age may also have greater negative socioeconomic impacts in affected patients. Therefore, more attention should be paid to the increasing prevalence of YOD, and optimizing treatment strategies for YOD patients is required. 
This review describes the epidemiology, clinical characteristics and issues associated with YOD. Since only a few epidemiologic data about YOD exist in South Korea, we evaluated the prevalence and characteristics of YOD using the Korean National Health Insurance Service (KNHIS) database.

\section{EPIDEMIOLOGY}

The prevalence of YOD is rapidly increasing worldwide. The International Diabetes Federation Diabetes Atlas reported that 63 million ( $16 \%$ of total adults with $\mathrm{T}_{2} \mathrm{DM}$ ) young adults aged 20 to 39 years had T2DM worldwide in 2013 [2]. The overall prevalence of YOD rose in most countries in 2017 compared with that in 2013, although this varied by region [1]. The increase in YOD was the largest in the Western Pacific, Africa, and Southeast Asia [3]. In a population-based study comparing the incidence rates among South Asian, Chinese, and Western populations, the incidence of YOD was the highest in South Asia, which was 2.2 times that of Western countries and 3.1 times that of China [4]. However, as the estimation of the prevalence from the Diabetes Atlas is based on the individual regional studies involved in the analysis, the known prevalence of YOD in different regions was dependent on the quality of the studies included.

The overall prevalence of youth-onset (age 10 to 19 years) $\mathrm{T} 2 \mathrm{DM}$ in the United States rose from $0.034 \%$ in 2001 to $0.046 \%$ in 2009 [5]. In Canada, the prevalence of youth-onset (age < 20 years) T2DM increased by 2.3-fold (from $0.009 \%$ to $0.021 \%$ ) over a decade (from 2002-2003 to 2012-2013) [6]. In a study using the Korea National Health and Nutrition Examination Survey (KNHANES) data, the overall (2005 to 2014) prevalence of diabetes was $0.2 \%$ among individuals aged 10 to 19 years and $0.9 \%$ among those aged 20 to 29 years [7]. The estimated prevalence of adults aged 30 to 39 years was $3.1 \%$ in men and $2.1 \%$ in women in 2014 [8], and $3.7 \%$ in men and $2.7 \%$ in women in 2018 in South Korea [9]. According to a national survey, the increasing prevalence of diabetes in young adults aged 20 to 39 years was also apparent in China: $3.2 \%$ in 2008 and $5.9 \%$ in 2013 [10].

\section{RISK FACTORS AND CLINICAL CHARACTERISTICS}

YOD shares common risk factors for late-onset T2DM. In this respect, it is evident that the increasing prevalence of YOD is associated with an increase in people who are overweight or obese worldwide [11,12]. According to the KNHANES study of 2005 to 2014, obese individuals aged 10 to 29 years showed a seven-fold higher prevalence of diabetes than non-obese individuals at the same age [7]. The prevalence of diabetes was $0.19 \%$, $0.34 \%$, and $1.06 \%$ among normal-weight, overweight, and obese South Korean adolescents aged 10 to 18 years, respectively [12].

The risk of diabetes is associated with unhealthy metabolic phenotypes as well as obesity. In a recent study using KNHIS database, among subjects with metabolic syndrome, the increased risk of incident diabetes was most prominent for young adults than older adults; 2.55-, 3.89-, and 6.31-times higher for young adults aged 20 to 39 years and 2.57-, 3.45-, and 5.18-times higher for adults aged 40 to 64 years with three through five components of metabolic syndrome [13]. It means higher association between impaired metabolic health and incident diabetes in young adults. In addition, the burden of metabolic and cardiovascular risk factors, such as higher triglyceride levels, apolipoprotein B levels, or high blood pressure, is more prominent in patients with YOD than in those with late-onset T2DM [14].

Compared with late-onset $\mathrm{T} 2 \mathrm{DM}$, patients with YOD have a higher prevalence of a family history of diabetes; the age at diagnosis of diabetes decreased by 1.7 years for every $10 \%$ increase in the number of family members with diabetes [15]. Individuals with YOD tend to have worse glycemic control represented by higher glycated hemoglobin (HbAlc) levels [16], poor responsiveness to oral glucose-lowering therapies, and shorter time to initiation of insulin treatment [17] than individuals with late-onset T2DM. This means that YOD have a more aggressive course of the disease than late-onset $\mathrm{T}_{2} \mathrm{DM}$ $[1,3,18]$. Rapid decline in $\beta$-cell function in YOD partly explains the rapidly worsening progression of the disease. In a previous study, $\beta$-cell function assessed by oral glucose tolerance test decreased by $20 \%$ to $35 \%$ per year in adolescent with T2DM [19], while it was by $7 \%$ per year in older adults with T2DM [20]. 


\section{BURDEN OF YOD: COMPLICATIONS AND HEALTH OUTCOMES}

YOD is associated with a much more frequent occurrence of diabetic complications and a more rapid progression of those complications than is observed in type 1 diabetes mellitus (T1DM) [21] or late-onset T2DM [1].

The Treatment Options for Type 2 Diabetes Mellitus in Adolescents and Youth (TODAY) study, a clinical trial conducted in the United States to maintain glycemic control in patients with youth-onset $\mathrm{T} 2 \mathrm{DM}$, indicated progressive changes in subclinical cardiac function, especially diastolic function, over 5 years in those with early-onset T2DM [22]. The risk of myocardial infarction in YOD was 14-fold higher than that in age-matched controls; however, in patients with late-onset T2DM, it was four times higher than that in age-matched controls [23].

In a study using a computer model simulation of the life course of a hypothetical cohort of youths and young adults in the United States, patients with YOD had a reduced average life expectancy of approximately 15 years than people without diabetes [24]. In a population- and registry-based study in Hong Kong, patients with YOD had double the hospitalization rate by age 60 years for any cause, including cardiovascular events, renal complications, and infections, compared with patients with late-onset T2DM [25]. A longer duration of follow-up due to early onset of disease in YOD may affect the high prevalence of complications or hospitalization in those patients. However, a study indicated that the effects of diabetes duration on health outcomes were greater in younger patients than in older patients [26].

Regarding microvascular complications, the longterm follow-up of the TODAY study with a mean diabetes duration of $13.3 \pm 1.8$ years reported that the incidence of diabetic kidney disease, neuropathy, and retinopathy was $54.8 \%, 32.4 \%$, and $13.7 \%$, respectively, in patients with YOD [27]. The SEARCH for Diabetes in Youth (SEARCH) study, a multicenter study of youths aged $<2$ o years with diabetes, reported significantly higher rates of diabetic kidney disease (19.9\% vs $5.8 \%$ ), retinopathy (9.1\% vs $5.6 \%)$, and peripheral neuropathy ( $17.7 \%$ vs $8.5 \%)$ in patients with YOD than in those with TiDM [21].

While studies generally showing a higher incidence of microvascular complications in YOD than in TiDM [21,28-31], whether the risk of microvascular complica- tions in YOD is higher than in late-onset $\mathrm{T}_{2} \mathrm{DM}$ is not conclusive. The incidence of nephropathy was comparable (the hazard rate ratio [HRR], 1.2; 95\% confidence interval [CI], 0.77 to 1.30), and the risk of retinopathy was lower (HRR, 0.42; 95\% CI, 0.24 to 0.74 ) in patients with youth-onset T2DM (age < 20 years) compared with older-onset group in Pima Indians [32]. In other studies, the overall prevalence of retinopathy was higher (84.3\% vs $72.8 \%$ ) in individuals with YOD than in those with late-onset $\mathrm{T} 2 \mathrm{DM}$ for diabetes duration $>20$ years, even though a lower age at diagnosis was not a significant predictor of diabetic complications [14,33]. A recent study showed that YOD is an independent risk factor for the development of proliferative diabetic retinopathy in T2DM patients with microalbuminuria [34].

\section{ISSUES OF YOD: ADHERENCE AND SOCIO- ECONOMIC FACTORS}

Suboptimal adherence to drugs or medical therapy in T2DM [35,36] increases the risk of diabetes complications, hospitalization, morbidity, and even mortality [37]. There is a substantial gap in the perception of disease entity and severity according to comorbidities in affected patients. Those recently diagnosed with T2DM often perceived the disease as a self-controllable condition. In contrast, patients with complications perceived it as more serious [38]. In this respect, younger T2DM patients without complications are more likely to perceive their medical condition lightly. Therefore, they are more likely to have poor health behaviors. The Australian National Diabetes Audit, a large national cross-sectional study for self-care practices among people with $\mathrm{T}_{2} \mathrm{DM}$, indicated that younger people are twice as likely than older patients not to follow the self-care practice recommendations, including dietary advice, taking regular medications, and self-monitoring of blood glucose levels [39]. Moreover, according to the TODAY study, the effect of high-quality lifestyle modifications did not persist for a long time in YOD patients [40]. A systematic review also indicated that adolescents (aged 10 to 20 years) were more likely to present poor compliance to medical treatment, as a result, had higher HbAic levels than older individuals [41]. According to the 2013 to 2014 National Health and Nutrition Examination Survey (NHANES) 
data, the younger the individual, the lower the rate of achievement of glycemic control (HbAic $\leq 7 \%$ ) [42].

Higher continuity of care for T2DM significantly reduces microvascular and macrovascular complications and the cost of diabetes treatment in patients with T2DM [43]. Non-attendance at diabetes outpatient appointments is related to suboptimal outcomes, and young adults, smokers, and cost problems were indicated as reasons for non-attendance [44]. In a South Korean study, the proportion of patients who visited the clinic regularly was lower in people with YOD than in those aged 40 to 80 years [45].

\section{YOD AMONG PEOPLE WITH NEW-ONSET T2DM IN SOUTH KOREA}

While the prevalence of YOD is reported to be increasing worldwide, there is little accurate epidemiologic information on YOD in South Korea. We evaluated the epidemiology and characteristics of new-onset T2DM according to age using the KNHIS database (Approval No. of Institutional Review Board: VC18ZNSIo243). This investigation included only patients with new-onset T2DM from 2009 to 2017. The included subjects were those who (1) were aged $\geq 20$ years; (2) received health checkups between January 1, 2009 and December 31, 2017; and (3) were not diagnosed with diabetes or treated with antidiabetic drugs before the checkups. Among them, those with a fasting plasma glucose (FPG) level of $\geq 126 \mathrm{mg} / \mathrm{dL}$ were defined as patients with new-onset T2DM. To define diabetic patients by FPG alone may be inaccurate, which may serve as a limitation of this study. However, in the absence of information about other additional tests, this definition was adopted because it is the only way to identify even undiagnosed patients. It is another limitation that the distinction between TiDM and T2DM might not be clear even though we used International Classification of Diseases-10 codes E11-14 when assessing the adherence to treatment of YOD. However, the incidence of $\mathrm{T} 1 \mathrm{DM}$ in adults aged $\geq 20$ years was 2.99 to 5.12 per 100,000 people between 2009 and 2013 [46], so little case of TiDM would be involved.

\section{Proportion of patients with YOD among those with new-onset T2DM}

Tables 1 and 2 show the number and proportion of patients with new-onset $\mathrm{T} 2 \mathrm{DM}$ according to age from 2009 to 2017 , respectively. In $2009,297,555$ (3.2\%) subjects were identified as having new-onset T2DM among 9,357,825 subjects who had received a national health checkup. Among them, 16.2\% (48,189/297,555) were young adults aged 20 to 39 years. The number and proportion of those with new-onset YOD remained steady for approximately 10 years. In 2017, 417,182 subjects had new-onset T2DM and 48,074 (11.6\% of new-onset T2DM) had new-onset YOD. The results did not provide convincing evidence about the increasing trends of YOD in the South Korean population. However, when only patients aged 20 to 29 years with YOD are considered, the proportion of those with new-onset $\mathrm{T}_{2} \mathrm{DM}$ is $1.9 \%$ to $3.2 \%$, which is higher than that reported in European studies and similar to that in South East Asian countries [1].

Table 1. New-onset type 2 diabetes mellitus of those who underwent health checkups according to different age groups (in years)

\begin{tabular}{lrrrrrrrrr}
\hline & \multicolumn{1}{c}{2009} & \multicolumn{1}{c}{2010} & \multicolumn{1}{c}{2011} & \multicolumn{1}{c}{2012} & \multicolumn{1}{c}{2013} & 2014 & 2015 & 2016 & 2017 \\
\hline $20-29$ & 9,512 & 8,003 & 7,996 & 6,961 & 7,486 & 7,441 & 7,358 & 7,815 & 7,924 \\
$30-39$ & 38,677 & 36,598 & 37,718 & 35,796 & 37,139 & 38,558 & 38,555 & 38,903 & 40,150 \\
$40-49$ & 81,208 & 81,139 & 83,375 & 83,857 & 86,528 & 95,429 & 99,429 & 101,837 & 104,934 \\
$50-59$ & 84,903 & 91,784 & 94,676 & 100,346 & 103,092 & 117,337 & 124,598 & 131,047 & 136,539 \\
$60-69$ & 53,396 & 54,797 & 52,112 & 54,108 & 56,330 & 65,077 & 70,052 & 78,780 & 82,508 \\
$\geq 70$ & 29,859 & 30,795 & 32,008 & 32,740 & 34,773 & 38,828 & 38,602 & 43,437 & 45,127 \\
Total & 297,555 & 303,116 & 307,885 & 313,808 & 325,348 & 362,670 & 378,594 & 401,819 & 417,182 \\
Total population & $9,357,825$ & $10,096,178$ & $10,432,011$ & $10,692,494$ & $10,830,785$ & $11,725,271$ & $11,910,666$ & $12,348,395$ & $12,535,317$ \\
\hline
\end{tabular}


Table 2. Proportion of new-onset type 2 diabetes mellitus of those who underwent health checkups according to different age groups (in years)

\begin{tabular}{|c|c|c|c|c|c|c|c|c|c|}
\hline & 2009 & 2010 & 2011 & 2012 & 2013 & 2014 & 2015 & 2016 & 2017 \\
\hline $20-29$ & 0.80 & 0.71 & 0.70 & 0.66 & 0.69 & 0.67 & 0.68 & 0.67 & 0.68 \\
\hline $30-39$ & 2.06 & 1.76 & 1.80 & 1.71 & 1.77 & 1.73 & 1.74 & 1.78 & 1.84 \\
\hline $40-49$ & 3.18 & 2.92 & 2.90 & 2.88 & 2.89 & 3.00 & 3.07 & 3.08 & 3.17 \\
\hline $50-59$ & $4 \cdot 35$ & 4.11 & 3.99 & 3.94 & 4.06 & 4.16 & $4 \cdot 31$ & $4 \cdot 39$ & $4 \cdot 49$ \\
\hline $60-69$ & 4.60 & $4 \cdot 49$ & 4.25 & 4.12 & 4.26 & $4 \cdot 34$ & $4 \cdot 39$ & $4 \cdot 5^{2}$ & $4 \cdot 5^{2}$ \\
\hline$\geq 70$ & 4.79 & 4.66 & $4 \cdot 44$ & 4.21 & $4 \cdot 37$ & $4 \cdot 40$ & $4 \cdot 32$ & $4 \cdot 50$ & $4 \cdot 44$ \\
\hline Total & 3.18 & 3.00 & 2.95 & 2.93 & 3.00 & 3.09 & 3.18 & 3.25 & $3 \cdot 33$ \\
\hline
\end{tabular}

\section{Clinical characteristics of patients with new-onset $\mathrm{T}_{2} \mathrm{DM}$ and YOD}

The mean age of patients with new-onset T2DM was $52.0 \pm 12.7$ and $53.7 \pm 12.2$ years in 2009 and 2017 , respectively (Table 3). The mean FPG level was $155.0 \pm 42.6$ in 2009 and $153.0 \pm 41.0 \mathrm{mg} / \mathrm{dL}$ in 2017 . The other demographic characteristics were also generally similar over time. On the other hand, the obesity status of those with new-onset T2DM changed substantially. The mean BMI was $25.1 \pm 3.4 \mathrm{~kg} / \mathrm{m}^{2}$ in 2009 and $26.0 \pm 3.8 \mathrm{~kg} / \mathrm{m}^{2}$ in 2017 . The mean waist circumference changed from $85.1 \pm 9.2$ to $87.0 \pm 10.3 \mathrm{~cm}$ between 2009 and 2017.

We observed that the mean FPG level and BMI were significantly higher in the YOD group than in the late-onset ( $\geq 40$ years old) T2DM group both in 2009 and 2017 (Table 3). The gaps in the mean FPG level and BMI between age groups were more profound in 2017 (Table 3), which indicates that patients with YOD had been getting more obese with poorer glycemic profile at the time of diagnosis over time. The mean FPG level increased from $157.6 \pm 47.7$ to $163.6 \pm 53.3 \mathrm{mg} / \mathrm{dL}$ and the mean BMI changed from $25.6 \pm 4.2$ to $28.1 \pm 5.2 \mathrm{~kg} / \mathrm{m}^{2}$ in people with YOD from 2009 to 2017 . Fig. 1 shows the distribution of FPG levels at the time of T2DM diagnosis according to age groups in 2009 (Fig. 1A) and 2017 (Fig. 1B). Notably, patients with YOD presented a higher proportion of high FPG levels at diagnosis than those with late-onset T2DM in 2017. For example, 22.0\% of patients with YOD had an FPG level of $\geq 180 \mathrm{mg} / \mathrm{dL}$, while $9.1 \%$ of patients aged $\geq 60$ years had an FPG level of $\geq 180 \mathrm{mg} /$ dL. In summary, we found that patients with YOD presented different phenotypes at diagnosis compared with those with late-onset T2DM. In particular, they tend to be more obese and have worse glycemic profiles, which is predicted to make the disease worse in the future, considering that the FPG level and BMI are important predictors of morbidity and mortality [47].

\section{Adherence to treatment of YOD}

We evaluated the clinic attendance rate which was defined as the proportion of people who visited clinics for diabetes management within 1 year after recognition of new-onset T2DM. Although the overall clinic attendance rate continued to increase from 2009 to 2017 in all age groups (Fig. 2), the clinic attendance rate of patient with YOD was only approximately half of that of late-onset T2DM. In 2017, it was the lowest in patients in their $20 \mathrm{~s}(18.6 \%)$ and the highest in patients in their $60 \mathrm{~s}(52.4 \%)$. The prescription rate of antidiabetic agents within a year after recognition of new-onset T2DM also continuously increased from 2009 to 2017 in all age groups (Fig. 3). However, the prescription rate for YOD was approximately one-third in 2009, and it was only about half of that of late-onset $\mathrm{T}_{2} \mathrm{DM}$ in 2017 . The prescription rate was the lowest in patients in their $20 \mathrm{~s}$ (11.8\%) and the highest in patients in their 6os (25.8\%) in 2017. Given that the FPG levels at diagnosis were significantly higher in patients with YOD than in those with late-onset $\mathrm{T} 2 \mathrm{DM}$, this poor adherence to clinical attendance and medical therapy of YOD is an alarming feature that needs urgent attention.

\section{CONCLUSIONS}

We summarized the epidemiologic, clinical character- 


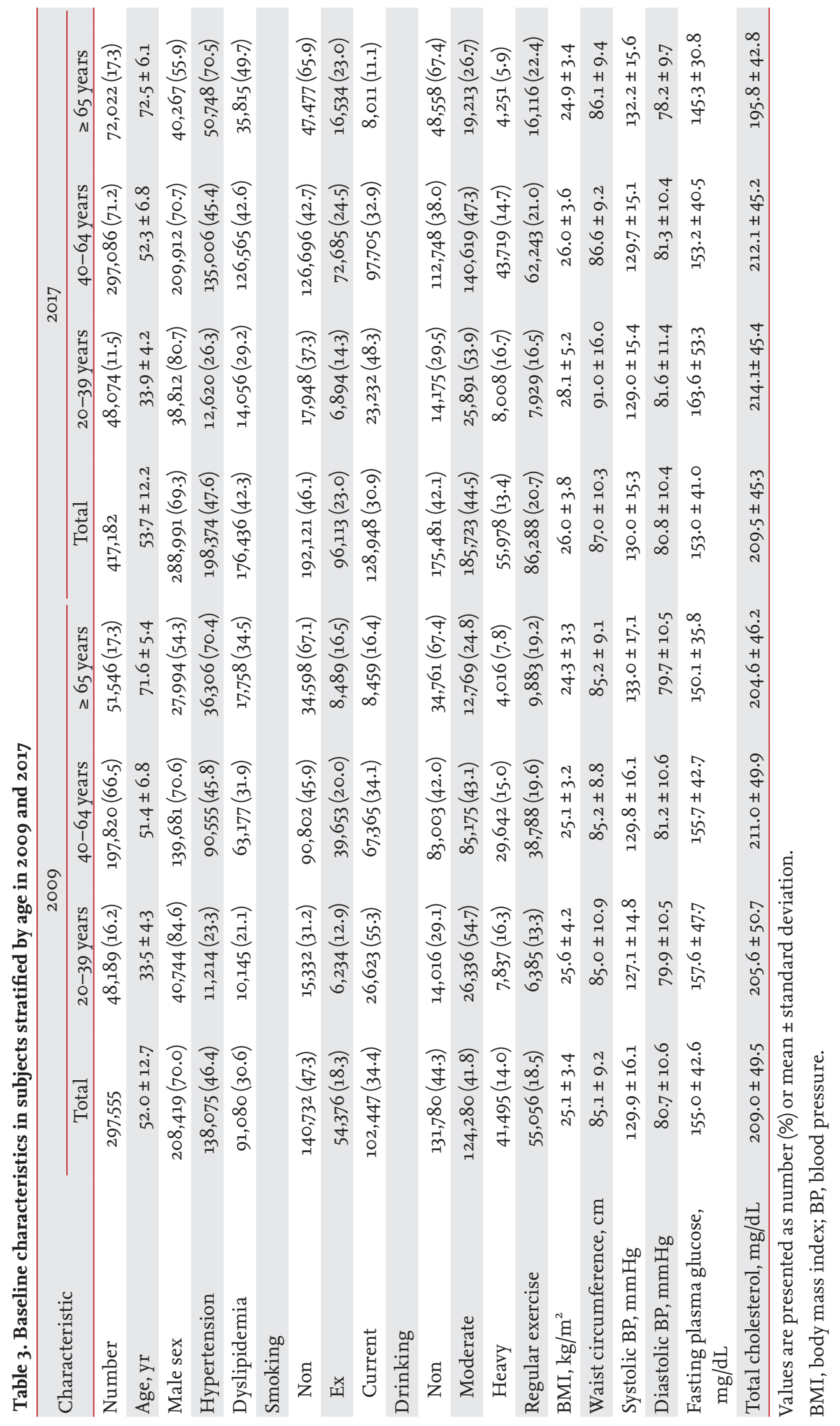




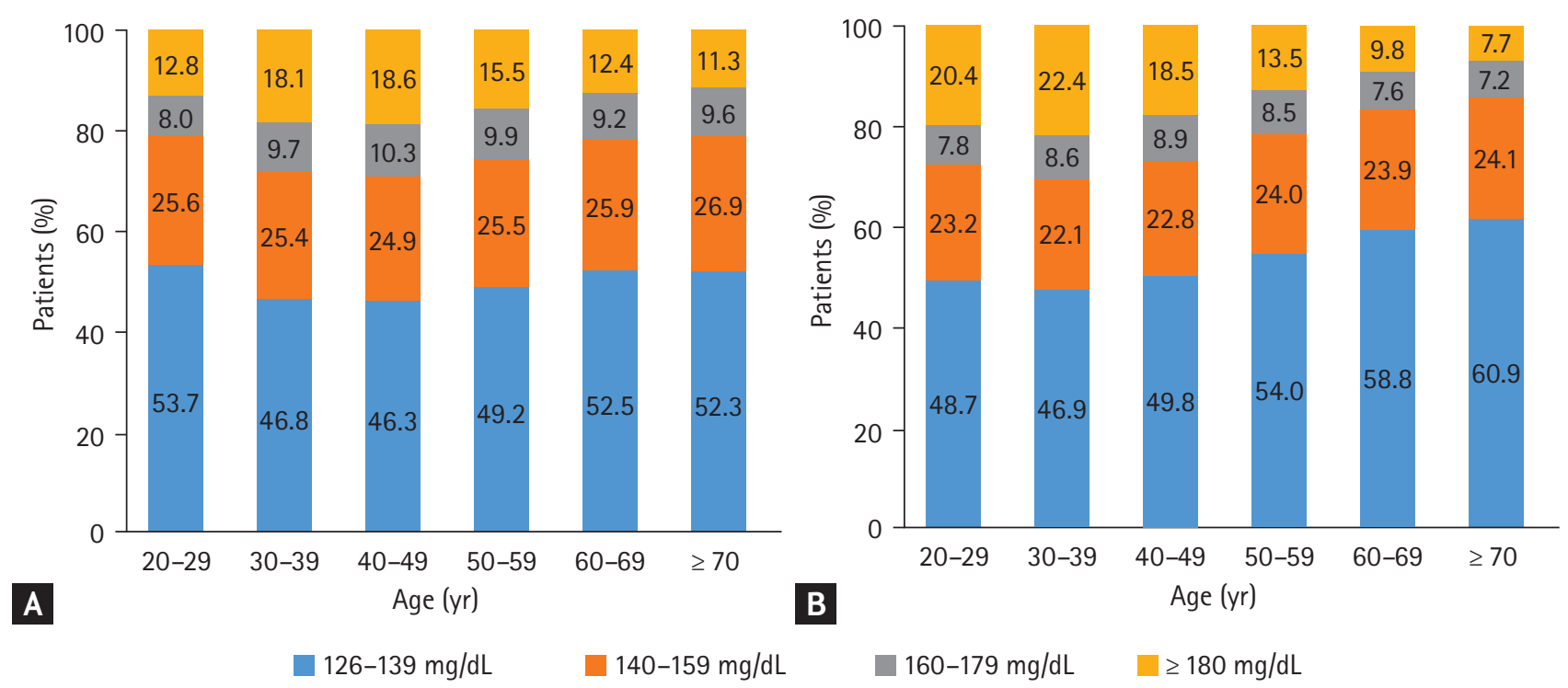

Figure 1. Distribution of blood glucose level in new-onset type 2 diabetes mellitus of those who underwent health checkups according to age group (A) in 2009 and (B) in 2017.

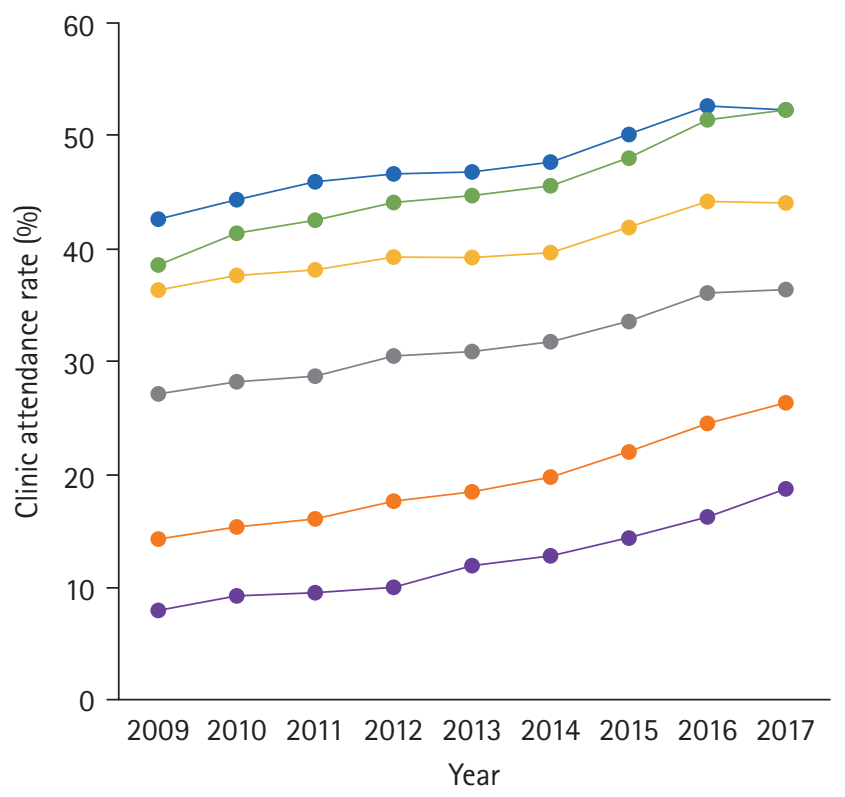

- 20-29 years

- 30-39 years

$$
\begin{array}{ll}
-40-49 \text { years } & -60-69 \text { years } \\
-50-59 \text { years } & -270 \text { years }
\end{array}
$$

Figure 2. Clinic attendance rate within 1 year after recognition of new-onset type 2 diabetes mellitus from 2009 to 2017 according to different age groups.

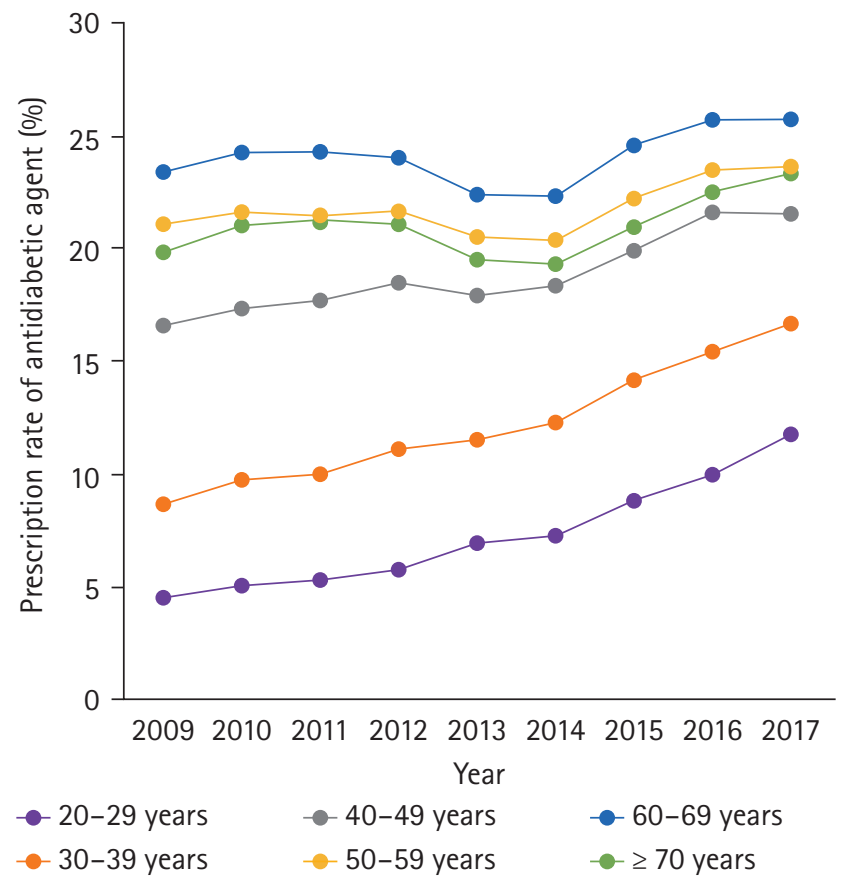

Figure 3. Prescription rate of antidiabetic agents within 1 year after recognition of new-onset type 2 diabetes mellitus from 2009 to 2017 according to different age groups. 
istics and health outcomes of YOD in this review. Evidence indicates that YOD has a different nature from the late-onset T2DM. A close association with severe obesity and impaired metabolic health as well as a rapid $\beta$-cell function decline of YOD defines it as a severe form of T2DM. As expected, early development of vascular complications is a characteristic of YOD, ultimately resulting in premature death. We also found that YOD patients are being more obese and presenting worse glycemia at their first presentation over time. Nonadherence to treatments and low compliance appear to be major obstacles to the proper management of YOD patients. Early detection and intensive management of YOD would be of paramount importance.

\section{Conflict of interest}

No potential conflict of interest relevant to this article was reported.

\section{Acknowledgments}

This research was supported by a grant of the Korea Health Technology R\&D Project through the Korea Health Industry Development Institute (KHIDI), funded by the Ministry of Health and Welfare, Republic of Korea (Grant Number: HI18Co275).

\section{REFERENCES}

1. Magliano DJ, Sacre JW, Harding JL, Gregg EW, Zimmet PZ, Shaw JE. Young-onset type 2 diabetes mellitus: implications for morbidity and mortality. Nat Rev Endocrinol 2020;16:321-331.

2. International Diabetes Federation. IDF Diabetes Atlas. 6th ed. Brussels (BE): International Diabetes Federation, 2013 .

3. Lascar N, Brown J, Pattison H, Barnett AH, Bailey CJ, Bellary S. Type 2 diabetes in adolescents and young adults. Lancet Diabetes Endocrinol 2018;6:69-80.

4. Ke C, Sohal P, Qian H, Quan H, Khan NA. Diabetes in the young: a population-based study of South Asian, Chinese and White people. Diabet Med 2015;32:487-496.

5. Dabelea D, Mayer-Davis EJ, Saydah S, et al. Prevalence of type 1 and type 2 diabetes among children and adolescents from 2001 to 2009. JAMA 2014;311:1778-1786.

6. Amed S, Islam N, Sutherland J, Reimer K. Incidence and prevalence trends of youth-onset type 2 diabetes in a cohort of Canadian youth: 2002-2013. Pediatr Diabetes 2018;19:630-636.

7. Cho EH, Shin D, Cho KH, Hur J. Prevalences and management of diabetes and pre-diabetes among Korean teenagers and young adults: results from the Korea National Health and Nutrition Examination Survey 20052014. J Korean Med Sci 2017;32:1984-1990.

8. Won JC, Lee JH, Kim JH, et al. Diabetes fact sheet in Korea, 2016: an appraisal of current status. Diabetes Metab J 2018;42:415-424.

9. Jung $\mathrm{CH}$, Son JW, Kang S, et al. Diabetes fact sheets in Korea, 2020: an appraisal of current status. Diabetes Metab J 2021;45:1-10.

10. Hu C, Jia W. Diabetes in China: epidemiology and genetic risk factors and their clinical utility in personalized medication. Diabetes 2018;67:3-11.

11. Nam GE, Kim YH, Han K, et al. Obesity fact sheet in Korea, 2019: prevalence of obesity and abdominal obesity from 2009 to 2018 and social factors. J Obes Metab Syndr 2020;29:124-132.

12. Kim JH, Lim JS. Trends of diabetes and prediabetes prevalence among Korean adolescents from 2007 to 2018. J Korean Med Sci 2021;36:e112.

13. Lee MK, Han K, Kwon HS. Age-specific diabetes risk by the number of metabolic syndrome components: a Korean nationwide cohort study. Diabetol Metab Syndr 2019;11:112.

14. Song SH, Hardisty CA. Early onset type 2 diabetes mellitus: a harbinger for complications in later years. Clinical observation from a secondary care cohort. QJM 2009;102:799-806.

15. Molyneaux L, Constantino M, Yue D. Strong family history predicts a younger age of onset for subjects diagnosed with type 2 diabetes. Diabetes Obes Metab 2004;6:187-194.

16. Hillier TA, Pedula KL. Characteristics of an adult population with newly diagnosed type 2 diabetes: the relation of obesity and age of onset. Diabetes Care 2001;24:1522-1527.

17. Mast R, Danielle Jansen AP, Walraven I, et al. Time to insulin initiation and long-term effects of initiating insulin in people with type 2 diabetes mellitus: the Hoorn Diabetes Care System Cohort Study. Eur J Endocrinol 2016;174:563-571.

18. Reynolds K, Saydah SH, Isom S, et al. Mortality in youth-onset type 1 and type 2 diabetes: the SEARCH for Diabetes in Youth study. J Diabetes Complications 
2018;32:545-549.

19. Kahn SE, Lachin JM, Zinman B, et al. Effects of rosiglitazone, glyburide, and metformin on $\beta$-cell function and insulin sensitivity in ADOPT. Diabetes 2011;60:1552-1560.

20. RISE Consortium; RISE Consortium Investigators. Effects of treatment of impaired glucose tolerance or recently diagnosed type 2 diabetes with metformin alone or in combination with insulin glargine on $\beta$-cell function: comparison of responses in youth and adults. Diabetes 2019;68:1670-1680.

21. Dabelea D, Stafford JM, Mayer-Davis EJ, et al. Association of type 1 diabetes vs type 2 diabetes diagnosed during childhood and adolescence with complications during teenage years and young adulthood. JAMA 2017;317:825835 .

22. TODAY Study Group. Longitudinal changes in cardiac structure and function from adolescence to young adulthood in participants with type 2 diabetes mellitus: the TODAY Follow-Up Study. Circ Heart Fail 2020;13:e006685.

23. Hillier TA, Pedula KL. Complications in young adults with early-onset type 2 diabetes: losing the relative protection of youth. Diabetes Care 2003;26:2999-3005.

24. Rhodes ET, Prosser LA, Hoerger TJ, Lieu T, Ludwig DS, Laffel LM. Estimated morbidity and mortality in adolescents and young adults diagnosed with type 2 diabetes mellitus. Diabet Med 2012;29:453-463.

25. Ke C, Lau E, Shah BR, et al. Excess burden of mental illness and hospitalization in young-onset type 2 diabetes: a population-based cohort study. Ann Intern Med 2019;170:145-154.

26. Zoungas S, Woodward M, Li Q, et al. Impact of age, age at diagnosis and duration of diabetes on the risk of macrovascular and microvascular complications and death in type 2 diabetes. Diabetologia 2014;57:2465-2474.

27. TODAY Study Group, Bjornstad P, Drews KL, et al. Longterm complications in youth-onset type 2 diabetes. $\mathrm{N}$ Engl J Med 2021;385:416-426.

28. Yoo EG, Choi IK, Kim DH. Prevalence of microalbuminuria in young patients with type 1 and type 2 diabetes mellitus. J Pediatr Endocrinol Metab 2004;17:1423-1427.

29. Dart AB, Sellers EA, Martens PJ, Rigatto C, Brownell MD, Dean HJ. High burden of kidney disease in youth-onset type 2 diabetes. Diabetes Care 2012;35:1265-1271.

30. Hollenberg NK. Higher incidence of diabetic nephropathy in type 2 than in type 1 diabetes in early-onset diabetes in Japan. Curr Hypertens Rep 2001;3:177.
31. Kahkoska AR, Isom S, Divers J, et al. The early natural history of albuminuria in young adults with youth-onset type 1 and type 2 diabetes. J Diabetes Complications 2018;32:1160-1168.

32. Krakoff J, Lindsay RS, Looker HC, Nelson RG, Hanson RL, Knowler WC. Incidence of retinopathy and nephropathy in youth-onset compared with adult-onset type 2 diabetes. Diabetes Care 2003;26:76-81.

33. Song SH, Gray TA. Early-onset type 2 diabetes: high risk for premature diabetic retinopathy. Diabetes Res Clin Pract 2011;94:207-211.

34. Lv X, Ran X, Chen X, et al. Early-onset type 2 diabetes: a high-risk factor for proliferative diabetic retinopathy (PDR) in patients with microalbuminuria. Medicine (Baltimore) 2020;99:e20189.

35. Krass I, Schieback P, Dhippayom T. Adherence to diabetes medication: a systematic review. Diabet Med 2015;32:725737.

36. Garcia-Perez LE, Alvarez M, Dilla T, Gil-Guillen V, Orozco-Beltran D. Adherence to therapies in patients with type 2 diabetes. Diabetes Ther 2013;4:175-194.

37. Ho PM, Rumsfeld JS, Masoudi FA, et al. Effect of medication nonadherence on hospitalization and mortality among patients with diabetes mellitus. Arch Intern Med 2006;166:1836-1841.

38. van Puffelen AL, Heijmans MJ, Rijken M, et al. Illness perceptions and self-care behaviours in the first years of living with type 2 diabetes: does the presence of complications matter? Psychol Health 2015;30:1274-1287.

39. Nanayakkara N, Pease AJ, Ranasinha S, et al. Younger people with type 2 diabetes have poorer self-care practices compared with older people: results from the Australian National Diabetes Audit. Diabet Med 2018;35:1087-1095.

40. Kaar JL, Schmiege SJ, Drews K, et al. Evaluation of the longitudinal change in health behavior profiles across treatment groups in the TODAY clinical trial. Pediatr Diabetes 2020;21:224-232.

41. Cramer JA. A systematic review of adherence with medications for diabetes. Diabetes Care 2004;27:1218-1224.

42. Comellas M, Marrero Y, George F, Matthews L. Age and glycemic control among adults with type 2 diabetes in the United States: an assessment from the National Health and Nutrition Examination Survey (NHANES) 2013-2014. Diabetes Metab Syndr 2019;13:3069-3073.

43. Nam JH, Lee C, Kim N, et al. Impact of continuous care on health outcomes and cost for type 2 diabetes mellitus: 
analysis using national health insurance cohort database. Diabetes Metab J. 2019;43:776-784.

44. Brewster S, Bartholomew J, Holt RIG, Price H. Non-attendance at diabetes outpatient appointments: a systematic review. Diabet Med 2020;37:1427-1442.

45. Kim YJ, Chon S, Oh S, Woo JT, Kim SW, Rhee SY. Analysis of diabetes quality assessment findings and future directions for the appropriate management of diabetes in Korea. Korean J Intern Med 2019;34:125-136.
46. Lee YB, Han K, Kim B, et al. High proportion of adult cases and prevalence of metabolic syndrome in type $1 \mathrm{di}$ abetes mellitus population in Korea: a nationwide study. Diabetes Metab J 2019;43:76-89.

47. Kim YS, Park YM, Han KD, Yun JS, Ahn YB, Ko SH. Fasting glucose level and all-cause or cause-specific mortality in Korean adults: a nationwide cohort study. Korean J Intern Med 2021;36:647-658. 